\title{
Developing a spouse version of the Illness Perception Questionnaire-Revised (IPQ-R) for husbands of women with rheumatoid arthritis
}

\author{
Katherine Regan Sterba ${ }^{a},{ }^{*}$ and Robert F. DeVellis ${ }^{b}$ \\ aBehavioral Sciences, School of Public Health, Austin Regional Campus, University of Texas, 313 \\ East 12th Street, Austin, TX 78701, US \\ bHealth Behavior and Health Education, University of North Carolina, CB 7280, Chapel Hill, NC \\ 27599-7280, US
}

\section{Abstract}

\begin{abstract}
A husband's beliefs about his wife's rheumatoid arthritis (RA) may be important to his provision of support and well-being. We adapted seven subscales of the Illness Perception QuestionnaireRevised to assess husbands' beliefs about their wives' RA. We recruited 190 couples (average years married $=22$; average years with $\mathrm{RA}=14$ ) from community settings to complete surveys assessing illness perceptions, psychosocial and illness variables at baseline and four-month followup. We conducted exploratory factor analyses, calculated Cronbach's alphas for each factor, and examined construct validity. This process yielded six parallel wife and husband subscales assessing beliefs about the (a) timeline, (b) consequences and (c) cyclical nature of RA, and women's RA (d) emotional responses, (e) control and (f) illness coherence. All items loaded above 0.50 on their respective factors and Cronbach's alphas ranged from 0.72 to 0.86 . Subscales were inter-related in a manner consistent with previous research and husbands' beliefs were related to a variety of illness and adjustment variables. The factor structure was replicated in the same sample at follow-up $(n=165)$. This study introduces an instrument to assess spouse beliefs about RA that may help to elucidate the role of spousal relationships in illness adaptation.
\end{abstract}

\section{Keywords}

illness perceptions; rheumatoid arthritis; spouses; initial validation

\section{Introduction}

According to Leventhal's Self-Regulatory Model (1984), beliefs about one's illness, or illness perceptions, are associated with coping and adjustment processes. Illness perceptions may be important to one's illness experience, health behaviour and health outcomes in arthritis (Pimm \& Weinman, 1998). The Illness Perception Questionnaire-Revised (IPQ-R) is an instrument to assess cognitive representations of a variety of illnesses including rheumatoid arthritis (RA) in individuals (Moss-Morris et al., 2002). The instrument has good psychometric properties and assesses the following nine illness perceptions (Moss-Morris et al., 2002): Identity (the description or view of symptoms involved with having the illness), Cause (ideas about what caused the illness), Timeline Acute/Chronic (beliefs about how long the illness will last), Timeline Cyclical (beliefs about the predictability or cyclic nature 
of illness), Personal Control (the extent to which an individual has control over illness), Treatment Control (beliefs about treatment effectiveness), Illness Coherence (extent to which an individual has a clear understanding of illness), Consequences (the expected effects of the illness), and Emotions (the emotional reactions to illness).

A few studies have compared the illness perceptions of spouses, highlighting the potential importance that illness perception congruence in partners may play in adjustment to a variety of chronic illnesses (e.g. Figueiras \& Weinman, 2003; Heijmans, DeRidder, \& Bensing, 1999; Sterba, et al., in press). These studies demonstrated that shared illness perceptions in spouses may have some effect on psychological and behavioural factors. For example, in our own work with couples coping with RA, couple congruence concerning women's personal control over RA and its cyclic nature predicted better psychological adjustment in women 4 months later (Sterba et al., in press). To study these processes further, it is important to refine the measurement of spouse illness perceptions. Studies examining the illness perceptions of spouses or caregivers (Figueiras \& Weinman, 2003; Heijmans et al., 1999; Sterba et al., in press) have used a modified version of the IPQ-R instrument but, to our knowledge, the properties of the modified version of the instrument have not been published.

This article describes the development and initial testing of a spouse version of seven subscales (Timeline Acute/Chronic, Personal Control, Treatment Control, Illness Coherence, Consequences, Emotions and Timeline Cyclical) of the IPQ-R designed to assess husbands' beliefs about their wives' RA. We aimed to develop a short instrument with parallel items for husbands and wives to enable researchers to compare illness perceptions in spouses. We (a) developed and tested a husband version of the IPQ-R, (b) examined the associations between corresponding wife and husband illness perceptions subscales, (c) examined the inter-relationships of the husband illness perceptions subscales, and (d) explored the relationships between each husband illness perceptions subscale and a variety of sociodemographic, marital, psychological and illness variables. We hypothesised that each husband illness perceptions subscale would be positively associated with each corresponding wife illness perceptions subscale. Furthermore, we hypothesised that husbands' illness perceptions would be structurally organised as in previous research (MossMorris et al., 2002). Specifically, we believed that optimistic illness beliefs would be associated with one another (e.g. believing RA had fewer consequences would be associated with believing one's wife had more control over her illness). Likewise, we believed that pessimistic illness perceptions would be associated with one another (e.g. stronger beliefs about the unpredictability of RA would be associated with believing wives had stronger emotional responses to their illness). Furthermore, because we hypothesised that a husband's illness beliefs were shaped by the characteristics of his wife's illness, we explored the ability of wife illness disability to predict each husband illness perceptions dimension. Finally, based on the caregiving literature that demonstrates a link between illness characteristics and burden in RA (e.g. Brouwer, et al., 2004), we hypothesised that optimistic husband illness perceptions would be associated with better psychological adjustment in husbands.

\section{Methods}

\section{Item development}

A pilot study was conducted to develop the husband version of the IPQ-R before testing the items in a larger survey study examining support in couples coping with RA (Sterba et al., in press). Existing intrapersonal illness perceptions items from the IPQ-R were adapted, reviewed by experts, and tested with a small sample of couples. We focused on seven of the IPQ-R's subscales: Timeline Acute/Chronic (six items), Personal Control (six items), Treatment Control (five items), Illness Coherence (five items), Consequences (six items 
from the IPQ-R and one additional item we added specific to the husband relationship), Emotions (six items) and Timeline Cyclical (four items). We excluded the Identity and Cause subscales of the IPQ-R to reduce respondent burden and because these subscales were factor analysed separately in previous work (Moss-Morris et al., 2002; Weinman, Petrie, Moss-Morris \& Horne, 1996). Each item from the IPQ-R was written from the perspective of the husband of the woman with RA. For example, when the patient was asked about the extent to which she agreed or disagreed with the following statement, 'My rheumatoid arthritis is very unpredictable', her spouse was asked to report the extent to which he agreed or disagreed with a similar statement, 'My wife's rheumatoid arthritis is very unpredictable'. Each item asked respondents to indicate the extent to which they agreed or disagreed with a statement on a six point scale (1 = Strongly Disagree, $2=$ Moderately Disagree, $3=$ Slightly Disagree, 4 = Slightly Agree, $5=$ Moderately Agree, $6=$ Strongly Agree). We chose to alter the IPQ-R's five-point response set to a six-point scale for two reasons (DeVellis, 2003). First, the absence of a midpoint potentially makes it more difficult for respondents to equivocate. Where there is a midpoint, respondents may select that option rather than thinking more carefully about the item and determining whether their sentiment leans more towards agreement or disagreement. Second, having six options potentially increases score variability and thus opportunities for those scores to covary with other variables. While these potential benefits of six rather than five response options are not guaranteed, we believed that they are sufficiently common to warrant the change in the response scale.

Higher scores on the Timeline Acute/Chronic subscale reflected partner beliefs that RA was permanent rather than temporary, and would last for a long period of time. Higher scores on the Personal Control subscale reflected stronger partner beliefs about women's personal control over RA. Higher scores on the Treatment Control subscale reflected stronger partner beliefs about the impact treatment had on women's RA. Higher scores on the Illness Coherence subscale reflected stronger partner beliefs about the extent to which women had a clear understanding of their RA. Higher scores on the Consequences subscale reflected stronger partner beliefs concerning the consequences of RA on women's lives. Higher scores on the Emotions subscale reflected partner beliefs that women had stronger emotional reactions associated with RA. Finally, higher scores on the Timeline Cyclical subscale reflected stronger partner beliefs about the unpredictability of RA.

After expert researchers reviewed the item wording, 10 married women with arthritis and their husbands were recruited from a local arthritis centre study database to complete mailed surveys containing the IPQ-R instruments. Partners were asked to provide written (as part of the questionnaire administration) and oral (as part of a follow-up telephone interview) feedback about their experience completing the survey. Both partners in six of the couples $(60 \%)$ returned completed questionnaires and participated in the follow-up telephone survey. Reasons for declining to participate in the pilot study included being too busy or having health problems. Respondents reported finding surveys easy to complete and understanding the instructions. Some participants reported burden from responding to multiple questions on the same topic, so items from the same subscale were not grouped together for the final survey. Pilot testing led to the modification of several items based on respondents' preferences or reports of awkward wording (e.g. the word 'which' was changed to 'that' for two items and the word 'condition' was changed to 'rheumatoid arthritis' for two items). Also, pilot testing led to the modification of the study protocol. For example, because one spouse reported feeling guilty about not understanding his wife's RA, we developed the protocol to encourage partners to complete surveys separately to promote honest responses. When item development was finalised, the psychometric properties of the new instrument were examined. 


\section{Participants and procedures}

Married women diagnosed with RA for at least one year and their husbands were recruited from a variety of community settings, including local arthritis education programmes, rheumatology clinics and arthritis websites (Sterba et al., in press). Each partner completed separate mailed surveys at baseline and four-month follow-up. We selected this timeframe to allow for the assessment of the direction of relationships among concepts and the stability of husband illness perceptions over potential symptom changes. One hundred and ninety couples completed surveys at baseline and 165 (87\%) of these couples completed follow-up surveys. The majority of participants were white (93\%) and most had at least some years of college education ( $81 \%)$. The average age for men was $51(S D=13.6)$, women had been diagnosed with RA for an average of 14 years $(S D=10.9)$, and couples had been married for an average of 22 years $(S D=14.9)$.

\section{Measures}

Both partners in couples completed illness perceptions instruments at baseline and followup. In addition, both partners reported on a variety of sociodemographic variables at baseline and adjustment and support variables at both time points. Wives also completed illness measures at both time points. Cronbach's alphas for measures in the current study are reported below.

\section{Arthritis functioning}

A composite score was calculated to examine arthritis disability in wives. Arm function, hand and finger function, household tasks, mobility, self-care, walking and bending and pain were assessed with the Arthritis Impact Measurement Scale (AIMS2; Meenan, Mason, Anderson, Guccione, \& Kazis, 1992). Because factor analyses revealed that all seven standardised average scores loaded onto one higher-order factor, the standardised average scores for each of the seven subscales were summed to calculate arthritis disability ( $a=$ 0.79). Higher scores represented more arthritis disability; women in this study sample had varied levels of arthritis disability $(M=13.3, S D=4.1$, range $=6.5-23.7)$.

\section{Psychological adjustment}

We computed a psychological adjustment composite score for husbands and wives. We assessed depression (Center for Epidemiologic Studies Depression Scale; Radloff, 1977; $a=$ 0.86 for husbands and $a=0.91$ for wives), optimism (the Life Orientation Test; Scheier \& Carver, 1985; $a=0.87$ and $a=0.88$ for husband optimism and pessimism and $a=0.82$ and $a=0.87$ for wife optimism and pessimism), positive and negative affect (Watson, Clark, \& Tellegen, 1988; $a=0.91$ and $a=0.86$ for husband positive and negative affect and $a=0.90$ and $a=0.89$ for wife positive and negative affect) and satisfaction with life (Diener, Emmons, Larsen, \& Griffen, 1985; $a=0.88$ husbands and $a=0.89$ wives) in husbands and wives. Because all scores of these scales loaded on one factor in factor analyses, a psychological adjustment composite score was calculated by summing each of the standardised average scores ( $a=0.82$ husbands and $a=0.80$ wives). Higher scores reflected better adjustment.

\section{Marital variables}

Marital satisfaction was assessed in both partners using the Kansas Marital Satisfaction Scale (Schumm et al., 1986; $a=0.97$ husbands and $a=0.96$ wives). In addition, perceptions of support over the past month were assessed with four items examining beliefs about spouse sensitivity to needs and interest in helping solve problems ( $a=0.92$ husbands and $a=0.93$ wives). 


\section{Sociodemographic variables}

Ethnicity, age, number of years married and number of years of education were assessed in the baseline questionnaire.

\section{Analyses}

Exploratory factor analyses were conducted on the illness perceptions items for husband and wife versions of the instruments with Promax rotation in SAS version 9.1. A variety of methods were used to decide how many factors to retain, including inspection of scree plots and eigenvalues (Nunnally, 1978). We retained items with standardised regression coefficients (i.e. factor loadings) over 0.5 when they also did not cross-load on any other factor greater than 0.3 (DeVellis, 2003). Next, we sequentially dropped items from both the husband and wife versions when they cross-loaded on more than one factor in either husband or wife analyses in an effort to establish short, reliable subscales with parallel items for both versions. Internal consistency was examined by computing Cronbach's alphas for each item grouping (Cronbach, 1951). To assess the stability of the original factor structure, we conducted additional exploratory factor analyses on the same set of items at 4-month follow-up. Test-retest reliability was also assessed with Pearson correlations of each of the subscales at baseline with corresponding subscales at 4-month follow-up. In addition, correlation matrices were used to explore construct validity by examining the interrelationships among the husband illness perceptions subscales and the relationships between each subscale and a variety of sociodemographic, marital, psychological and illness variables $(p<0.05)$. Consistent with the original work developing the IPQ-R (Moss-Morris et al., 2002), we also examined the associations between each of the husband IPQ-R subscales and positive and negative affect. To demonstrate that the husband IPQ-R subscales reflected unique RA-related constructs rather than general affect, we expected null to small correlations between each husband IPQ-R subscale and positive and negative affect. Further, we examined the associations between wife illness disability and each of the husband illness perceptions dimensions over time using multiple regression models. Because we did not have specifically relevant extant theory to guide the selection of control variables for our regression models, we included sociodemographic and illness variables associated with any of our outcomes of interest (husband beliefs about wives' RA at follow-up) $(p \leq 0.1)$. Final control variables in these models included husband education and baseline level of the outcome variable for each model (e.g. husband illness perceptions subscale). Finally, to explore predictive validity, we examined the associations between each of the baseline husband illness perceptions subscales and husband psychological adjustment over time. We first ran separate models for each husband illness perceptions subscale and then included all husband illness perceptions subscales together in one model, to examine the ability of each husband illness perceptions subscale to predict psychological adjustment independently and in the presence of other illness beliefs. Again, without theory to guide the selection of control variables for our regression models, we included sociodemographic and illness variables associated with husband psychological adjustment at follow-up $(p \leq 0.1)$, and included husband age, husband education, number of years married, wife illness disability and baseline level of husband psychological adjustment in final models.

We acknowledge that there are advantages and disadvantages to including an initial score as a covariate in a regression model, especially in an ongoing condition such as RA (Hewett, Anderson, \& Minor, 1992). While several approaches have been suggested for dealing with data such as these, we have used the pre-score as a covariate in our regression models to best capture our intent to examine later psychological adjustment after accounting for initial level of psychological adjustment as recommended by Hewett and colleagues (1992). 


\section{Results}

\section{Factor analyses}

For the 39 husband illness perceptions items, initial factor analysis revealed 11 factors (11th eigenvalue $=1.03$ ) explaining $66.6 \%$ of the total variance (communalities were fixed at 1.0 for all analyses) with eight items cross-loading on more than one factor. For the 39 wife illness perceptions items, factor analysis revealed 10 factors $(10$ th eigenvalue $=1.06$ ) explaining $66.6 \%$ of the total variance with nine items cross-loading on more than one factor. As described above, an iterative process was used to examine the effects of dropping cross-loading items from both husband and wife versions of the instrument. Items were excluded when they failed to load on only one factor at 0.5 or higher in both versions. Refactoring the retained items yielded parallel 28 -item, six-factor solutions for wife and husband item sets explaining $60.3 \%$ of the total variance $(6$ th eigenvalue $=1.42$ ) for the wife version and $59.2 \%$ of the total variance (6th eigenvalue $=1.49$ ) for the husband version. Factor loadings ranged from 0.52 to 0.83 for items in the husband set and from 0.50 to 0.88 for items in the wife set (see Table 1 for husband items and factor loadings). Final parallel male and female instruments included a five-item Timeline Acute/Chronic subscale ( $a=$ 0.86 for husbands and $a=0.75$ for wives), a six-item Control subscale ( $a=0.77$ for husbands and $a=0.79$ for wives), a five-item Illness Coherence subscale ( $a=0.80$ for husbands and $a=0.83$ for wives), a four-item Consequences subscale ( $a=0.76$ for husbands and $a=0.77$ for wives), a four-item Emotions subscale ( $a=0.78$ for husbands and $a=0.86$ for wives), and a four-item Timeline Cyclical subscale ( $a=0.72$ for husbands and $a=0.73$ for wives). Four of the subscales - Timeline Acute/Chronic, Illness Coherence, Emotions, and Timeline Cyclical - were equivalent to those in the IPQ-R. The Control subscale, however, combined three of the IPQ-R's Personal Control items with three Treatment Control items. Further, the Consequences subscale omitted two of the IPQ-R items and added our new item specific to the husband relationship ('My wife's rheumatoid arthritis causes difficulties for me'). Finally, the Emotions subscale omitted two of the IPQ$\mathrm{R}$ items. Descriptive statistics and Cronbach's alphas for the husband version are shown in Table 2.

Additional exploratory factor analyses of the 39 wife and husband items at four-month follow-up $(n=165)$ replicated the six-factor baseline factor structure with one exception. One item ('My rheumatoid arthritis has major consequences for my life') in the Consequences subscale in the wife version cross-loaded onto two factors and did not load greater than 0.5 in the husband version ('My wife's rheumatoid arthritis has major consequences for her life'). Cronbach's alphas at four-month follow-up ranged from 0.71 to 0.86 for the husband subscales (Table 2) and from 0.75 to 0.87 for the wife subscales.

\section{Bivariate associations}

In examining test-retest reliability, we found that each husband IPQ-R subscale at baseline was positively associated with its corresponding subscale at four-month followup (Table 2). In addition, each of the six husband illness perceptions subscales was positively associated with each corresponding wife subscale $(r=0.27, p=0.0001$ for Timeline Acute/Chronic; $r=$ 0.26, $p=0.0003$ for Control; $r=0.40, p<0.0001$ for Illness Coherence; $r=0.49, p<0.0001$ for Consequences; $r=0.42, p<0.0001$ for Emotions; and $r=0.25, p=0.0004$ for Timeline Cyclical). Further (Table 3), a husband's beliefs about his wife's control over RA was inversely associated with his beliefs about the timeline (acute/chronic) and consequences of RA and his beliefs about his wife's emotional reactions to RA. A husband's beliefs about the degree to which his wife had a clear understanding of her RA were inversely associated with his beliefs about the unpredictability and consequences of RA and his beliefs about his wife's emotional responses to RA, and positively associated with his beliefs about the acute/ 
chronic timeline of RA. Finally, a husband's beliefs about his wife's emotional responses to RA were also positively associated with his beliefs about the unpredictability and consequences of RA.

Relationships between husband illness perceptions and sociodemographic, adjustment, and support variables are shown in Table 3. Few sociodemographic variables were associated with husband illness perceptions. Husband education was modestly positively associated with beliefs about the acute/chronic timeline of RA and beliefs about wife's personal control over RA. Furthermore, husband age was inversely associated with husband beliefs about the unpredictability of RA. Arthritis disability was inversely associated with husband beliefs about wife's control over RA, and positively associated with husband beliefs about the consequences of RA. Wife perceptions of support were inversely associated with husband beliefs about wives' emotional reactions to RA, and positively associated with beliefs about how much control wives had over RA. Wife marital satisfaction was inversely associated with husband beliefs about wives' emotional reactions to RA and positively associated with husband beliefs about the extent to which wives had a clear understanding of their RA. Husband and wife psychological adjustment were each inversely associated with husband beliefs about the consequences of RA and husband beliefs about wives' emotional reactions to RA. Finally, wife psychological adjustment was positively associated with husband beliefs about wives' control over RA and husband beliefs about the acute/chronic timeline of RA.

Table 3 also shows associations between each of the husband IPQ-R subscales and positive and negative affect. Husband negative affect was positively associated with beliefs about the consequences of RA and wives' emotional reactions to RA. Furthermore, husband positive affect was inversely associated with husband beliefs about the consequences of RA.

\section{Regression models}

In separate models examining the ability of wife disability at baseline to predict husband beliefs at 4-month follow-up, we found that wife disability at baseline predicted husband beliefs about the consequences of RA $\left(B=0.04, S E B=0.02, \beta=0.15, p=0.02, \Delta R^{2}=\right.$ $0.02)$ and wives' control over RA $\left(B=-0.04, S E B=0.02, \beta=-0.16, p=0.02, \Delta R^{2}=0.03\right)$ at 4-month follow-up, controlling for husband education and baseline levels of husband illness perceptions. Wife disability did not predict husband beliefs about the timeline of RA, the unpredictable nature of RA, wives' emotional reactions to RA, or wives' illness coherence.

In separate models examining the ability of each baseline husband illness perceptions subscale to predict husband psychological adjustment at four-month follow-up, husband beliefs about wives' control over RA at baseline marginally predicted greater psychological adjustment in husbands four months later $\left(B=0.44, S E B=0.22, \beta=0.09, p=0.05, \Delta R^{2}=\right.$ 0.01 ), controlling for baseline levels of psychological adjustment, husband education and age, wife disability and number of years married. No other husband illness perceptions subscales predicted husband psychological adjustment over time when examined in separate models. Likewise, when all six baseline husband illness perceptions subscales were included in one model predicting husband psychological adjustment at follow-up, only husband beliefs about wives' control over RA were significant, controlling for baseline levels of psychological adjustment, husband education and age, wife disability and number of years married (Table 4). In these analyses, because the correlations among the six illness perceptions dimensions ranged from not significant to modest (i.e. all correlations were $<0.44$ ), we determined that multicollinearity was not a concern in the final model presented in Table 4 (Voss, 2005). 


\section{Discussion}

A new adapted husband version of some of the subscales of the IPQ-R was developed in this study; the new six-subscale instrument was easy to administer, reliable, and stable over a four-month period in our sample of husbands whose wives had RA. Our goal was to adapt the IPQ-R instrument to enable researchers to compare illness perceptions in partners, a potentially important area of research with respect to coping and support. Six subscales resulted from the seven IPQ-R subscales that were tested. Four of the subscales were equivalent to IPQ-R subscales. However, two of our final husband subscales, Consequences and Emotions, had fewer items than the same subscales in the IPQ-R. This was because in our analyses, we dropped items that did not fare well in both husband and wife versions of the instrument. Also, items from the Personal Control and Treatment Control subscales factored together in a Control subscale. The original Illness Perception Questionnaire (Weinman et al., 1996) also had a general Control subscale but later factor analyses for the revised IPQ-R divided items from this subscale into the Treatment and Personal Control subscales (Moss-Morris et al., 2002). However, in these analyses, the authors found that two items from the Treatment Control subscale also cross-loaded (i.e. loaded at 0.5) onto the Personal Control subscale and suggested that the distinction between Personal and Treatment Control may be more or less relevant depending on the illness (Moss-Morris et al., 2002). Our results may also suggest that individuals view RA control differently in their partners than in themselves.

The baseline factor structure of the husband instrument was replicated at four-month followup with the exception of one item in the Consequences subscale not performing well at follow-up. Because the smaller sample size at follow-up in our study may have played some part in this inconsistency, we recommend that the Consequences subscale - and this item ('my wife's rheumatoid arthritis has major consequences for her life') in particular - be examined in future studies.

In general, consistent with our hypotheses, the six resulting subscales were structurally organised as in previous research (Moss-Morris et al., 2002). Most optimistic illness beliefs were associated with one another (e.g. believing RA had fewer consequences was associated with believing one's wife had more control over her illness, less severe emotional reactions to RA, and a more coherent picture of her illness) and most pessimistic illness beliefs were associated with one another (e.g. believing RA was more unpredictable was associated with believing one's wife had stronger emotional reactions to RA and a less coherent picture of her illness). Surprisingly, believing one's wife's RA was more unpredictable, was not related to a husband's beliefs about his wife's control over her illness and the consequences of RA. This suggests that judgments about illness unpredictability for another person may be isolated from one's beliefs about the impact of the illness on patients. Further, as hypothesised, we found that in general, having more optimistic illness perceptions in husbands was associated with less severe disability in wives and better psychological adjustment in both partners. Specifically in regression analyses, illness disability in wives at baseline predicted husbands believing RA had more consequences and their wives having lower control over their RA four months later. However, wife disability did not predict husband beliefs about the timeline of RA, the unpredictable nature of RA, wives' emotional reactions to RA, or wives' illness coherence, suggesting that these beliefs in husbands may be independent of the characteristics of RA. Also, in line with research showing that partners can experience burden from caring for a loved one with RA (e.g., Brouwer et al., 2004), we found that a husband's beliefs about his wife's control over RA at baseline marginally predicted his psychological adjustment at four-month follow-up. Other illness perceptions in husbands did not predict their subsequent adjustment, which may reflect the special importance of beliefs concerning control as determinants of adjustment. 
Contrary to our hypotheses, husband beliefs about the acute/chronic timeline of RA were not associated with other subscales as expected (e.g. believing RA had a longer timeline was not associated with beliefs about women's emotional reactions to RA or the consequences of RA). These null findings may have resulted from very low variability in husband responses to the Timeline Acute/Chronic subscale in this study $(M=5.6, S D=0.79)$. In this sample, most husbands believed RA was a permanent and chronic condition. However, despite the low variability in husbands' responses to this subscale, we did find that husbands believing RA had a longer timeline also believed their wives had less control over their RA and more illness coherence, suggesting that even small variations in beliefs about RA's timeline are sensitive to these particular beliefs. Future study should examine husband illness perceptions in samples with more acute conditions.

Few sociodemographic variables were associated with husband illness perceptions. Husband education level was modestly positively associated with husband beliefs about the timeline (acute/chronic) of RA and wife's control over RA, and husband's age was modestly inversely associated with beliefs about the unpredictability of RA, indicating that one's experiences may affect one's views of certain characteristics of the illness. We also found that wives perceived their husbands as more supportive when the latter viewed their wives as having fewer emotional reactions to RA and greater control over the illness. Likewise, wife marital satisfaction was associated with husbands believing their wives had fewer emotional reactions to RA and a more coherent picture of their illness. This may suggest that husbands who see their wives as dealing more effectively with the illness are judged as more supportive. In line with previous IPQ-R research (Moss-Morris et al., 2002), we found that certain husband illness perceptions subscales had small correlations with positive and negative affect. More specifically, a husband's beliefs about RA's consequences was positively associated with his negative affect and inversely associated with his positive affect. Further, a husband's beliefs about his wife's emotional reactions to RA were positively associated with his negative affect. No other associations between illness beliefs and affect emerged, suggesting that the husband illness perceptions subscales capture some judgment or process, presumably cognitive, which is not closely aligned with affective states.

A limitation of this study was that we did not assess the Identity or Cause subscales of the IPQ-R, therefore overlooking illness perceptions concerning the symptoms that individuals associate with their illness and its cause. Because these two illness perceptions dimensions have been shown to be important to coping and adjustment in RA (e.g. Pimm \& Weinman, 1998), developing husband-focused subscales to assess them would contribute to research in this area. Further, because in this study only wives had RA, future study should examine illness perceptions in other relationship configurations. For example, it is unclear whether the perceptions of well wives of husbands with RA would follow the present pattern of findings.

Despite limitations, this study had several strengths including its methods and focus. With two study time points, we were able to replicate the factor structure found at baseline and look at predictive validity over time. Further, we collected data from both partners in couples, allowing us to analyse the factor structure of both partner versions of the instruments together. Finally, we developed items for the husband version with input from researchers, clinicians and couples in which one partner had arthritis. With further study, this adapted instrument will enable researchers to compare illness perceptions in partners and assess the impact of couple illness perception congruence on coping, adjustment, and support. 


\section{Acknowledgments}

This work was supported by a Doctoral Dissertation grant from the Arthritis Foundation, a Predoctoral training grant from the Thurston Arthritis Research Center (National Institute of Arthritis and Muskuloskeletal and Skin Diseases grant 5-T32-AR07416), and a Postdoctoral Fellowship from the Cancer Prevention and Control Training Program, Center for Health Promotion and Prevention Research at the University of Texas-Houston School of Public Health (National Cancer Institute/NIH grant 2R-25-CA-57712). The content is solely the responsibility of the authors and does not necessarily represent the official views of the National Cancer Institute or the National Institutes of Health. The authors wish to thank the experts who reviewed the adapted items in the item development phase of the study.

\section{References}

Brouwer WBF, van Exel NJA, van de Berg B, Dinant HJ, Koopmanschap MA, van den Bos GAM. Burden of caregiving: Evidence of objective burden, subjective burden, and quality of life impacts on informal caregivers of patients with rheumatoid arthritis. Arthritis Care and Research. 2004; 51(4):570-577. [PubMed: 15334429]

Cronbach LJ. Coefficient alpha and the internal structure of tests. Psychometrika. 1951; 16:297-334.

DeVellis, RF. Scale development: Theory and applications. 2. Vol. 26. Newbury Park: Sage Publications; 2003.

Diener E, Emmons RA, Larsen RJ, Griffen S. The satisfaction with life scale. Journal of Personality Assessment. 1985; 49(1):71-75. [PubMed: 16367493]

Figueiras MJ, Weinman J. Do similar patient and spouse perceptions of myocardial infarction predict recovery? Psychology and Health. 2003; 18(2):201-216.

Heijmans M, DeRidder D, Bensing J. Dissimilarity in patients' and spouses' representations of chronic illness: Exploration of relations to patient adaptation. Psychology and Health. 1999; 14:451-466.

Hewett JE, Anderson SK, Minor MA. Statistical analyses for research in arthritis when assessing change. Arthritis Care and Research. 1992; 5(2):74-80. [PubMed: 1390967]

Leventhal, H.; Nerenz, DR.; Steele, DS. Illness representation and coping with health threats. In: Baum, A.; Singer, JE., editors. Handbook of psychology and health. Vol. IV. New York: Erlbaum; 1984. p. 221-252.

Meenan RF, Mason JH, Anderson JJ, Guccione AA, Kazis LE. AIMS2. The content and properties of a revised and expanded Arthritis Impact Measurement Scales Health Status Questionnaire. Arthritis and Rheumatism. 1992; 35(1):1-10. [PubMed: 1731806]

Moss-Morris R, Weinman J, Petrie KJ, Horne R, Cameron LD, Buick D. The revised illness perception questionnaire (IPQ-R). Psychology and Health. 2002; 17(1):1-16.

Norton R. Measuring marital quality: A critical look at the dependent variable. Journal of Marriage and the Family. 1983; 45:141-151.

Nunnally, JC. Psychometric theory. 2. New York: McGraw Hill; 1978.

Pimm TJ, Weinman J. Applying Leventhal's self regulation model to adaptation and intervention in rheumatic disease. Clinical Psychology and Psychotherapy. 1998; 5:62-75.

Radloff LS. The CES-D Scale: A self-report depression scale for research in the general population. Applied Psychological Measurement. 1977; 1(3):385-401.

Scheier MF, Carver CS. Optimism, coping, and health: Assessment and implications of generalized outcome expectancies. Health Psychology. 1985; 4(3):219-247. [PubMed: 4029106]

Schumm WR, Paff-Bergen LA, Hatch RC, Obiorah FC, Copeland JM, Meens LD, et al. Concurrent and discriminant validity of the Kansas Marital Satisfaction Scale. Journal of Marriage and the Family. 1986; 48:381-387.

Sterba KR, DeVellis RF, Lewis MA, DeVellis BM, Jordan JM, Baucom DH. Effect of couple illness perception congruence on psychological adjustment in women with rheumatoid arthritis. Health Psychology. in press.

Voss, SD. Multicollinearity. In: Kempf-Leonard, K., editor. Encyclopedia of social measurement. Vol. II. San Diego, CA: Academic Press; 2005. p. 759-770. 
Watson D, Clark LA, Tellegen A. Development and validation of brief measures of positive and negative affect: The PANAS scales. Journal of Personality and Social Psychology. 1988; 54(6): 1063-1107. [PubMed: 3397865]

Weinman J, Petrie KJ, Moss-Morris R, Horne R. The illness perception questionnaire: A new method for assessing the cognitive representation of illness. Psychology and Health. 1996; 11:431-445. 


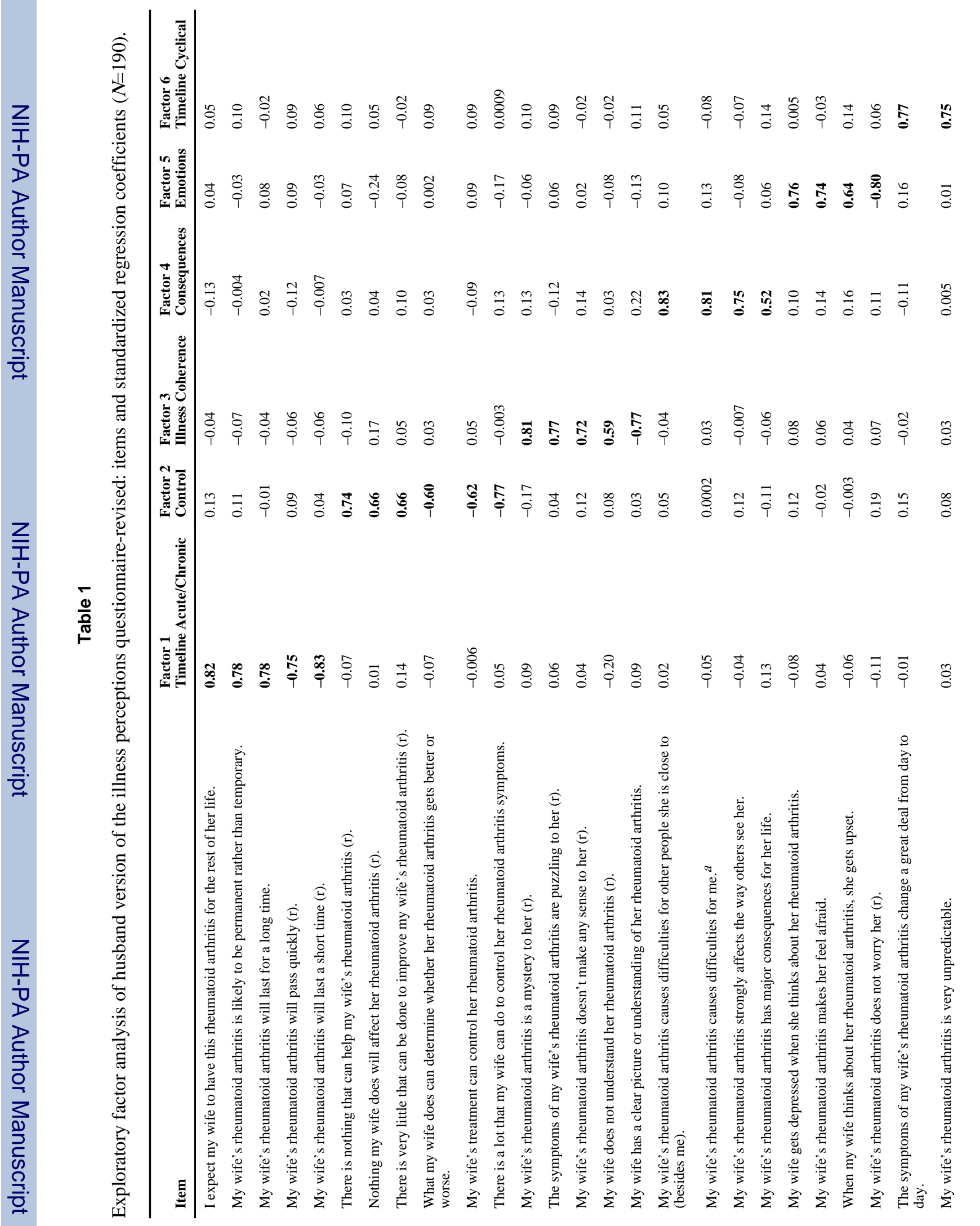




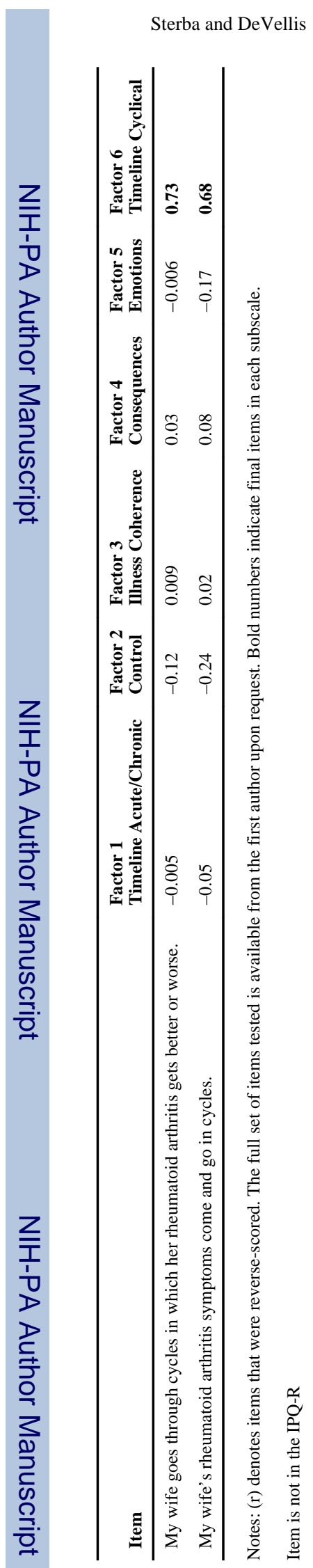

Psychol Health. Author manuscript; available in PMC 2013 January 19. 


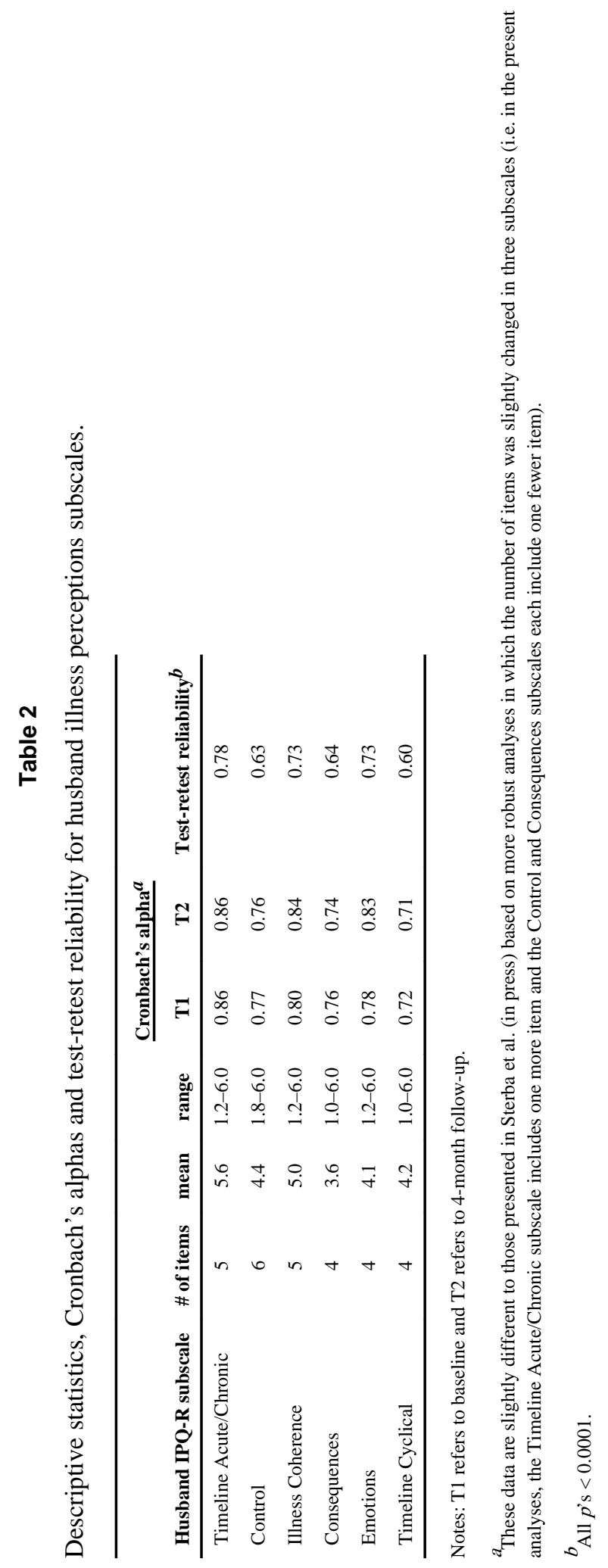

Psychol Health. Author manuscript; available in PMC 2013 January 19. 


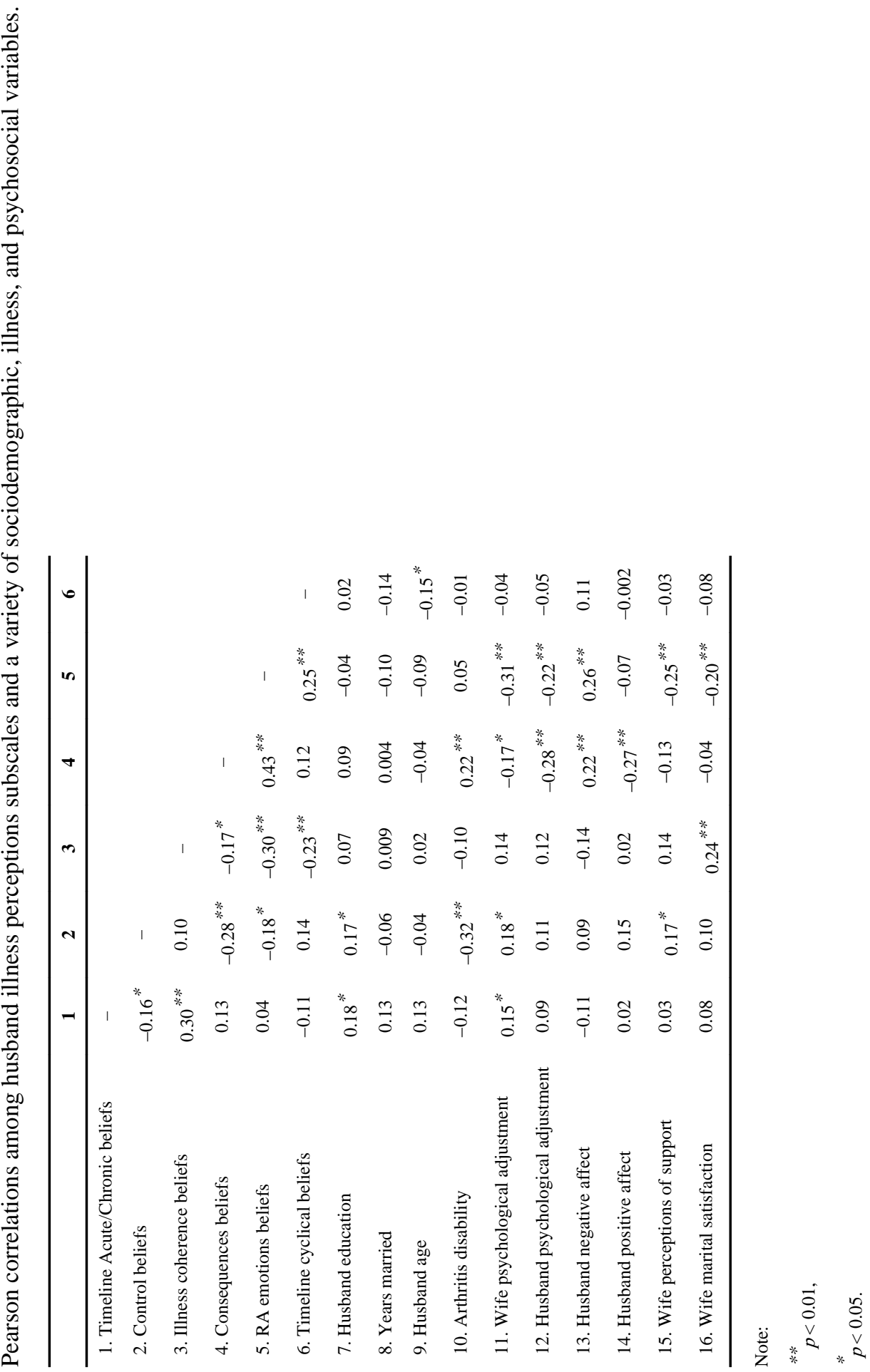




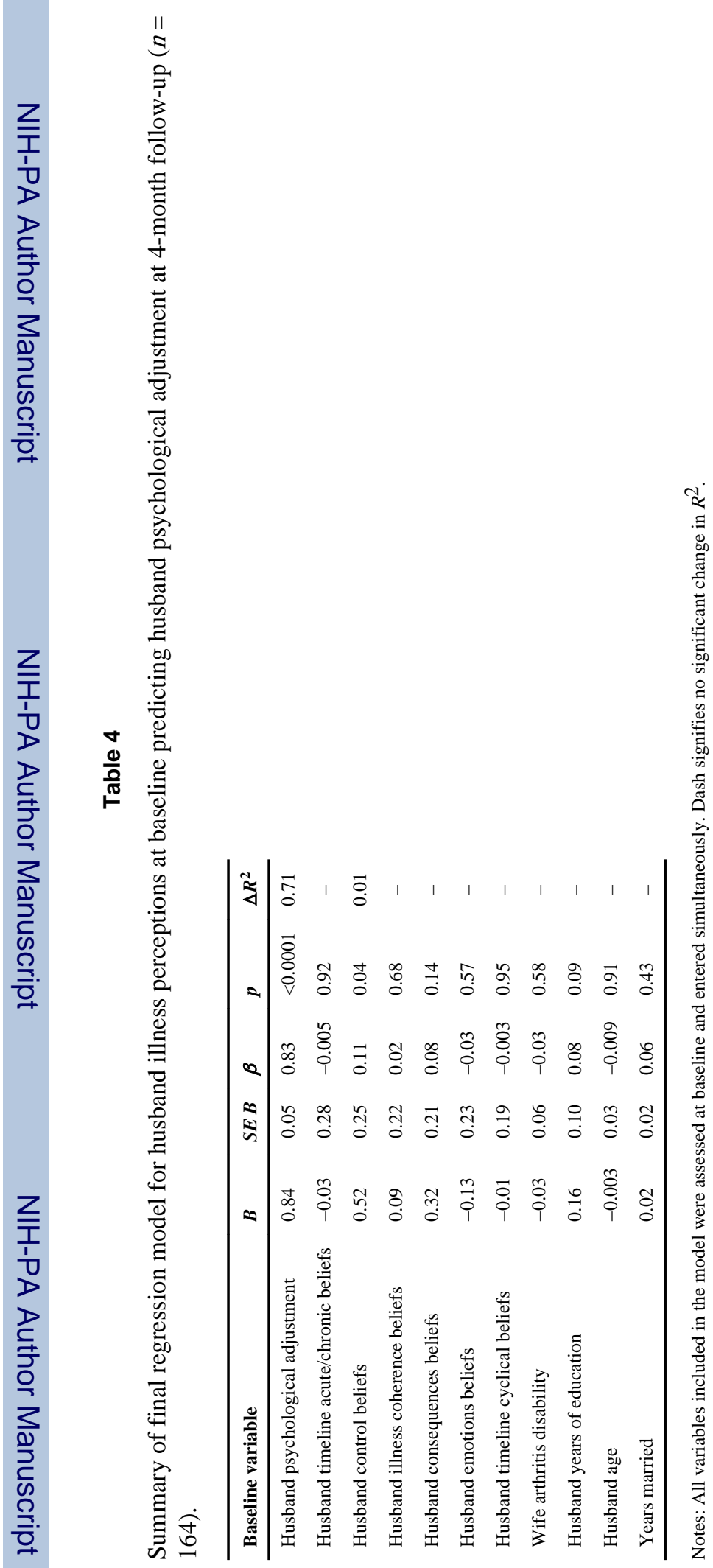

Psychol Health. Author manuscript; available in PMC 2013 January 19. 